\title{
Evaluation of a community based service for urgent psychiatric assessment
}

\author{
M. J. Crawford, D. Kohen and J. Dalton
}

\begin{abstract}
The Urgent Asessement Service (UAS) was set up to provide communily bosed ungent poychiotile cascesement to a range of referrers. The work of the service was aseceseed over a six month perlod. Results show that if was popular with a broad range of medical and non-modical protestionats. Potionts genercilly presented with depreseston or peychotic illnesies and thoes relerred from non-medicel sources were more likely to be suffering from schizophrenla and assessed as being of least as unwell as those referred by GPs and hospltal based doctors. Rates of referral to hosplit services were low with the vast majortly of pationts being reterred back to their general practitioner afier inilifil cescesement and treatment.
\end{abstract}

An important consequence of the shift in the pattern of services for those with mental illness away from a central hospital base has been the enormous diversification in the number and types of agencies catering for the needs of these patients (Jones, 1979). Recent Government legislation has supported these changes by assigning different responsibilities in the care of patients to medical and non-medical service providers (Department of Health, 1989). Despite numerous changes in service provision the needs of patients have in many ways remained the same. One such primary need is for urgent assessment at times of crises. Traditionally this service was organised through reception centres associated with in-patient psychiatric units or through the accident and emergency department of general hospitals. However, it can be argued that these environments, because of their base within the hospital setting, are not ideal for assessing the needs of patients whose care is increasingly delivered by community based workers (Schuster, 1995).

This article describes a community based service for urgent assessment - the Urgent Assessment Service (UAS) - and examines its performance over a six month period. The UAS serves the adult (18 to 65) population of north Islington in London, an inner city area with the sixth highest Jarman indices in England and Wales. It is staffed by a full-time Community
Mental Health Nurse and a part-time psychiatrist. Referrals could be made during working hours five days a week and patients were assessed, jointly, three mornings a week. The service aimed to provide initial assessments within 72 hours of receiving the referral and patients were seen at the local Community Mental Health Centre or on domiciliary visits. During the planning stages of the service the question of whether referrals should be restricted to those from GPs and hospital based doctors was discussed. It was decided that in order to best meet the needs of all patients referral should be open to the full range of other community based health care professionals and directly to patients and carers through self-referral.

It was hoped that by integrating the process of assessment with those working in the community, the process of referral and subsequent community based treatment would be facilitated, and that as a result some referrals could be redirected from a busy hospital liaison/Accident and Emergency (A\&E) service operating in the same area.

\section{The study}

This study aimed:

(a) to examine the source of referral to see how such a service would be used by the range of potential referrers

(b) to report on the nature and severity of the problems with which people presented, to ensure that those being referred from the range of different sources presented with problems that were both urgent and requiring the involvement of the service

(c) to examine the types of treatment used and the outcome of interventions in order to evaluate if it was possible to manage the needs of this group of patients without recourse to hospital services.

A 23-item data sheet was completed which included demographic variables, details about 
the referrer, mental state and diagnoses of the patient, management and an 11-item scale of level of disturbance based on the fourth draft of the Health of the Nation Outcome Scale (HoNOS) (March 1994). This scale measures a range of disability and disturbance of mental state such as presence of hallucinations and factors such as problems in the social environment. It has been described as a "psychiatric thermometer" and been recommended as a useful tool for both clinical practice and medical audit (Calman, 1994). The data presented are a comprehensive summary of all the cases seen in the first six months of the service. Data analysis was carried out using the Statistical Package for Social Sciences (SPSS).

For the purpose of analysis different referrers were grouped into four main categories of general practitioners, hospital doctors (comprising liaison psychiatrists and general adult psychiatrists), community workers (community mental health nurses, housing support workers, social workers and probation officers) and self-referrals. Differences in mean levels of disturbance between groups were analysed using one way ANOVA.

\section{Findings}

During this six month period, 147 patients were referred to the service and 105 patients were offered appointments. Of the 42 patients not offered appointments the two most common

Table 1. Source of referral

\begin{tabular}{llc}
\hline Referrer & \multicolumn{2}{c}{ Patients assessed } \\
\hline General practitioner & $n$ & $\%$ \\
CMHN \& other community & 37 & 47 \\
workers & 18 & 23 \\
Hospltal based doctors & 16 & 20 \\
Direct (from patient or carer) & 7 & 9 \\
Unknown & 1 & 1 \\
\hline
\end{tabular}

reasons were that they lived outside the catchment area of the service, or that the presenting problem was not considered to require urgent assessment and alternative services were suggested. Of the 105 offered appointments the age range was 18 to 63 with a mean of 36 years. Approximately half were female ( $n=56 ; 53 \%)$ and the majority had had no previous contact with services ( $n=45 ; 57 \%)$. Thirtysix did not attend for their appointment and 79 were actually assessed (a non-attendance rate of $25 \%)$. The following data refer to the 79 patients who were assessed. The two most common sources of referral (Table 1) were local GPs and non-medical community workers.

The most commonly stated reason for referral was concern about deteriorating mental state despite current treatment $(57 \%)$, but risk of selfharm (23\%) and concern about harm to others (14\%) were also raised. Concern about the delay involved in using other services (2\%), prevention of relapse $(2 \%)$, and the belief that the patient was making inappropriate use of GP services (2\%) were rarely stated as reasons for referral.

Table 2 shows the ICD-10 (WHO, 1992) diagnoses of those referred. The most common diagnosis was of depressive illness mild/moderate followed by schizophrenia and bipolar affective disorder. Smaller numbers of patients presented with problems related to neurotic illnesses and drug and alcohol misuse.

In addition, Table 2 shows a breakdown of diagnosis in patients referred to the service by GPs and community workers, the two largest sources of referral to the service. Results showed that of 18 patients referred by community workers the mean total HoNOS score was 10.7 (95\% CI 9.72-11.84), of the 37 referred by their GP the mean score was 8.1 (95\% CI 7.00-9.28). The seven patients referred by the $A \& E$ liaison team had a mean score of 7.0 and of the seven who referred themselves, or those they cared for, directly to the service the mean score was $\mathbf{5 . 2}$ (95\% CI 3.24-7.33) ( $F=9.46, P=0.003)$. Patients referred by community workers were more likely to have a diagnosis of a schizophrenia than those

Table 2. ICD-10 diagnosis of those assessed

\begin{tabular}{|c|c|c|c|c|c|c|}
\hline \multirow[b]{2}{*}{ Diognosis (ICD-10) } & \multicolumn{2}{|c|}{ Total } & \multicolumn{2}{|c|}{ GP referral } & \multicolumn{2}{|c|}{ Community worker reterral } \\
\hline & $n$ & $\%$ & $n$ & $\%$ & n & $\%$ \\
\hline \multicolumn{7}{|l|}{ Psychotic disorders } \\
\hline Schizophrenia (F20.0-9) & 17 & 21 & 5 & 13 & 11 & 61 \\
\hline BAD-depressed (F31.3-6) & 14 & 18 & 9 & 24 & 2 & 11 \\
\hline BAD-mania (F30.0-1) & 4 & 5 & 0 & 0 & 0 & 0 \\
\hline \multicolumn{7}{|l|}{ Non-psychotic disorders } \\
\hline Depression mild/moderate (F32.0-1) & 22 & 28 & 12 & 32 & 5 & 28 \\
\hline Adjustment disorder (F43.0-2) & 8 & 10 & 5 & 13 & 0 & 0 \\
\hline Neurotic disorder (F40-4l) & 7 & 9 & 2 & 5 & 0 & 0 \\
\hline Alcohol/drug (F10-19) & 7 & 9 & 4 & 11 & 0 & 0 \\
\hline
\end{tabular}


Table 3. Treatment interventions offered by the UAS in this sample

\begin{tabular}{lrr}
\hline Treaiment intervention & $\boldsymbol{n}$ & $\%$ \\
\hline Pharmacological & 35 & 43 \\
No change & 19 & 24 \\
Start antidepressant & 6 & 8 \\
Increase antidepressant & 9 & 11 \\
Start antipsychotic & 7 & 9 \\
Increase antipsychotic & 3 & 3 \\
Decrease/stop meds & & \\
Psychosocial & 34 & 43 \\
No change & 13 & 16 \\
Counselling (voluntary sector) & 15 & 18 \\
CMHN input & 5 & 6 \\
Alcohol/drug service & 4 & 5 \\
Psychologist & 2 & 3 \\
Day centre & 6 & 8 \\
Social services & & \\
\hline
\end{tabular}

referred by their GP $\left(\chi^{2}=11.1, P<0.01\right)$. Analysis of level of disturbance indicated that this group was at least as disturbed as those referred by their GP (mean HoNOS score of those with schizophrenia and referred by $\mathrm{GP}=11.2(95 \%$ C.I. 4.5-17.9), and score of those referred by community worker $=11.5(95 \%$ C.I. 10.2-12.8)).

In terms of intervention, $75 \%$ were offered follow-up from the service with a mean of three appointments. Table 3 indicates the other treatment interventions, both psychological and physical.

With regard to disposal, $75 \%$ ( $n=59$ ) were referred back to the care of their GP with $16 \%$ $(n=13)$ being referred to psychiatric out-patient clinics and one patient to the local day hospital (1\%). The number of patients admitted to inpatient services was two (3\%). In the remaining $5 \%$ of cases, patients were still being provided a service prior to final disposal.

\section{Comment}

During the first six months of the operation of this new service, it became clear that it was successful in attracting referrals from a broad range of agencies. Although GPs were the main source of referral, a wide range of community based workers were also frequent users of the service. Given the important role of GPs in 'flitering' referrals to secondary services, it has been argued that patients requiring urgent assessment should first be assessed at the primary health care level (Whittaker \& Appleby, 1995). The finding that patients or their relatives who referred themselves directly to the service had the lowest levels of disturbance would support this view.

The finding that patients referred by community workers were more disturbed than those referred by their GP is of interest. While the higher rates of schizophrenia in those referred by community based workers reflects the caseload of CMHNs and housing support workers, levels of disturbance among these patients were just as high as in patients with schizophrenia referred by their GP. This finding supports the comments of Marriott et al (1993) that other professionals with non-medical training may also be able to serve as efficient 'gate-keepers' to secondary services.

The results of this study show that the majority of patients seen had problems requiring urgent assessment of their mental health. Almost half those referred had a diagnosis of a psychotic illness $(23 \%$ with bipolar affective disorder and $21 \%$ with schizophrenia). A further $28 \%$ were referred with depression of mild/moderate severity and those with adjustment disorder made up only $10 \%$ of those seen. We consider it important to provide a range of facilities to GPs and that supporting them in the management of patients with non-psychotic depression is an appropriate role of this service.

The rate of hospital admission at $3 \%$ is low when compared to other services providing urgent assessments of mental health (Whittaker \& Appleby, 1995). An important factor in explaining this was the continued work of the local A\&E service. The UAS is not seen as a substitute for the $A \& E$ service whose role includes facilitating admission to hospital for those in crisis. Similarly, patients referring themselves with minor problems are usually advised to see their GP and GP referrals of patients with non-urgent problems can often be directed towards the out-patient services.

The scope of this study has been limited both in time and depth. Results may prove to be atypical when compared with longer periods. To gain a more complete understanding of the impact of this service on other services, longitudinal data on patients seen in $A \& E$ and out-patients are required.

However, data collected so far suggest that the Urgent Assessment Service can usefully fill a gap between out-patient and emergency services. In addition it can offer the possibility of facilitating the process of urgent mental health assessment to a range of referrers and of integrating subsequent treatment in the community.

\section{References}

CALMAN, K. C. (1994) HoNOS: a psychiatric thermometer. CMO's Update, 4, 7. 
DEPARTMENT OF HEALTH (1989) NHS and Community Care Act. London: HMSO.

JONES, K. (1979) Integration or disintegration in the menta health services. Joumal of the Royal Society of Medicine. 72, 640-648.

MARRIOTr, S., MALONE, S., ONYETT, S., et al (1993) The consequences of an open referral system to a community mental health service. Acta Psychiatrica Scandinavica. 88, 93-97.

SCHUSTER, J. M. (1995) Psychiatric consultation in the general hospital emergency department. Psychiatric Services, 46, 555-557.

WHITTAKER, J. F. \& APPLEBY, L. (1995) A psychiatric emergency walk-in clinic: a dangerous substitute to primary care? Psychiatric Bulletin, 19, 129-134.
WORLD HEALTH ORGANIZATION (1992) The Tenth Revision of the International Classification of Diseases and Related Health Problems (ICD-10). Geneva: WHO.

Michael Crawford, Research Fellow, Department of Psychological Medicine, Maudsley Hospital; "Dora Kohen, Consultant Psychiatrist, 2nd Floor. East Wing, Homerton Hospital, Homerton Row. London E9 6SR; Joy Dalton, Consultant Psychiatrist, Whittington Hospital, Highgate Hill, London N19 5NF

*Correspondence

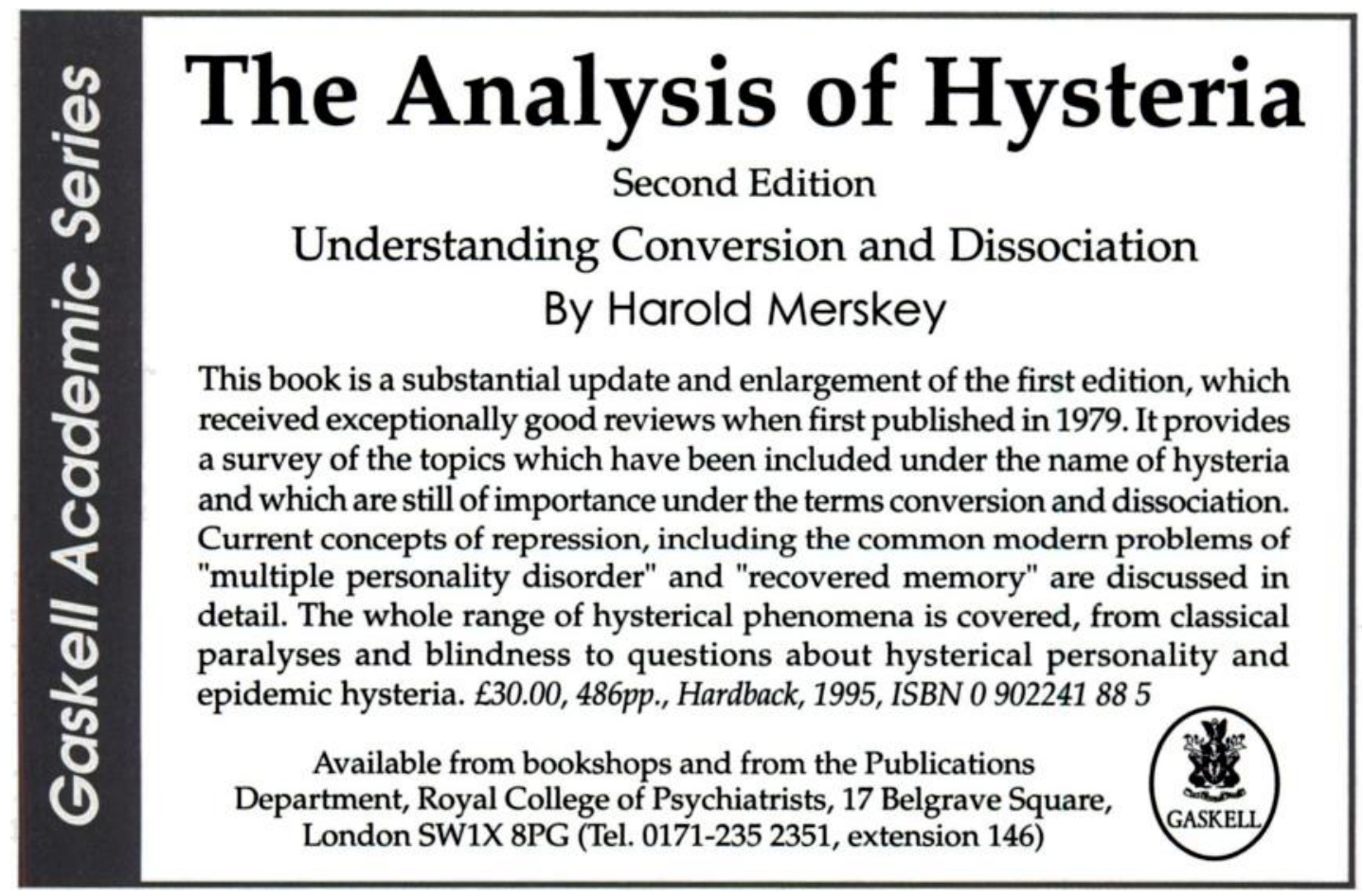

